\title{
System Frequency Monitoring in the Nigerian Power System
}

\author{
Luigi Vanfretti, Student Member, IEEE, Usman Aliyu, Member, IEEE, \\ Joe H. Chow, Fellow, IEEE, and James A. Momoh, Fellow, IEEE
}

\begin{abstract}
Frequency is one of the most important measures of the state of a power system, especially for structurally weak and rapidly growing power systems. Thus, frequency monitoring is a desirable practice to ensure reliability and provide data for analysis. This paper reports the joint work between Abubakar Tafawa Balewa University (ATBU) and Rensselaer Polytechnic Institute (RPI) to study frequency dynamics of a relative small power system. We describe the Frequency Disturbance Recorder (FDR) implementation experience at ATBU, Bauchi, Nigeria, and present analysis on the digital recordings obtained by the FDR. A proposal for a university-based frequency monitoring network for the Nigerian power system is also presented. Such monitoring system will allow further investigations on the Nigerian system and ultimately enhance the understanding of the dynamics and control of structurally weak and rapidly growing power systems found in many developing countries.
\end{abstract}

Index Terms-Technology transfer, developing nation, Frequency Monitoring Network, Frequency Disturbance Recorder

\section{INTRODUCTION}

$\mathbf{M}$ Onitoring of frequency in power networks provides insight on the characteristics of system dynamics, due to the fact that in steady state, frequency is common throughout the system [1]-[3]. In particular, in a rapidly growing power system constrained by insufficient generating capacity, frequency can be very sensitive to disturbances and control actions.

Rensselaer Polytechnic Institute (RPI) and Abubakar Tafawa Balewa University (ATBU) have established a collaboration to study the dynamics of a rapidly growing power network typified by the Nigerian power system. A frequency disturbance recorder (FDR) has been installed at ATBU and several recordings have been made, some of which are analyzed in this paper, revealing interesting operation and dynamic characteristics.

Howard University (HU) in Washington DC and the University of Benin (Uniben) in Nigeria have also established an international research collaboration under the International Research Engineering and Education (IREE) Program sponsored by the National Science Foundation (NSF). The research aspect of the collaboration is aimed at advancing the Voltage Stability Margin (VSM) measurement using optimization methods to achieve real-time control. For this work, a FDR

L. Vanfretti and J. H. Chow are with the Department of Electrical, Computer, and Systems Engineering, Rensselaer Polytechnic Institute, Troy, NY 12180, USA. (e-mail: vanfrl@rpi.edu, chowj@rpi.edu).

U. Aliyu is with Abubakar Tafawa Balewa University, Bauchi, Nigeria. (e-mail: uoaliyu@yahoo.com)

J. Momoh is with Howard University, Washington, DC 20059. (e-mail: jmomoh@howard.edu)

978-1-4244-4241-6/09/\$25.00 @2009 IEEE was provided to Uniben and for real-time data acquisition that is required for the VSM computations.

The characteristics of the Nigerian power system seen from ATBU suggest the need for improvement of frequency control. This is a concern because Nigeria is in the process of deregulating its electricity market [4]. Tighter frequency control is crucial to provide adequate signals to the real-time market and avoid fluctuating energy prices.

To enhance the understanding of the Nigerian power system and to apply this knowledge to other rapidly growing power networks, we propose a Nigerian university-based frequency monitoring network for in-depth characterizations of the system frequency behavior engendered by various system disturbances. The Nigerian university frequency monitoring network, if fully operational, could be replicated for other electric utilities in developing nations for the sole aim of deepening the current understanding of the dynamics and control of structurally weak electric power networks.

The remainder of the paper is organized as follows. In Section II we provide the background on the RPI-ATBU collaboration, describe the implementation experience gained at ATBU, and present some FDR data analysis from recordings made at Bauchi, Nigeria. A proposal for a university-based frequency monitoring network is decribed in Section III, where logistic and reliability issues of this monitoring system are also discussed.

\section{FDR IMPLEMENTATION AND DATA ANALYSIS}

\section{A. FDR Implementation Experience}

To obtain actual dynamic system and control characteristics of the Nigerian Power System, researchers from RPI provided a frequency disturbance recorder manufactured at Virginia Institute of Technology and State University to ATBU researchers. The FDR digitally records the voltage from a $230 \mathrm{~V}$ wall socket outlet. The voltage measurement is time tagged using the GPS signal. From the voltage measurement, frequency can be computed. The data rate of 10 samples per second is captured with a personal computer and can be transmitted over the internet to the frequency monitoring network (FNET) server at Virginia Institute of Technology and State University VTech), Blacksburg, Virginia, USA.

Figure 1 shows the low-voltage power supply installation and data transfer set-up adopted by the ATBU's researchers. The power supply for the FDR consists of a $230 \mathrm{~V}$ supply rail, two programmable switches, two PSU (Power Supply Unit) and an UPS (Uninterruptible Power Supply). The programmable switches are used to switch on the FDR for scheduled data gathering. The PSU units are used to convert 


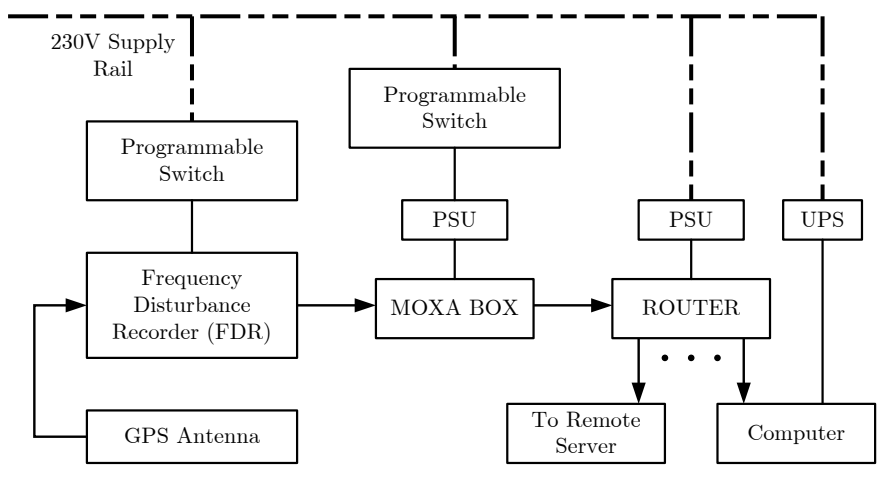

Figure 1. ATBU FDR Installation Set-up

voltage and frequency from a $230 \mathrm{~V} / 50 \mathrm{~Hz}$ to a $110 \mathrm{~V} / 50 \mathrm{~Hz}$ supply. Note that the FDR was designed for operation at either power supplies. The Ethernet devices (serial device server and router) used in the installation, however, are not designed for $230 \mathrm{~V} / 50 \mathrm{~Hz}$. The data transfer set-up consists of a serial device server (MOXA Box [7]) extracting data from the FDR through the serial port and sending it to a router. The router is enabled to send data to VTech's Information Management System (IMS) server and allows a dedicated PC to receive the information for local storage.

Several difficulties were encountered for the implementation of the FDR. Aside from the logistic problems, there were two major drawbacks. Initially, it was desirable to have a continuous stream of data flowing from ATBU to VTech's IMS server. This would have provided continuous data storage. However, it was found after several tests that there was a large amount of data losses in the data transfer from Africa to the US. Thus it was decided that the data would be locally recorded with a PC at ATBU and then the recordings were sent to RPI via email. Figure 2 shows a screen shot of the FDR small server program retrieving data from ATBU's FDR.

The second obstacle concerns the identification of lost data. The initial installation of the FDR had large amounts of lost information due to the loss of GPS signal. Initially it was difficult to identify the missing samples in the data because the FDR small server did not have a sample tagging capability. The pinpointing of lost data was possible after this deficiency in the software was presented to VTech's researchers who created a time index feature, allowing pinpointing of the missing samples in the data. The GPS signal loss was solved by simply relocating the FDR to another area with better signal reception.

At Uniben, the voltage stability research requires the installation of the FDR in the electrical engineering laboratory for voltage and frequency signals to be monitored and recorded over time. These signals were to be used as input for testing the FDR based Voltage Stability Margin computation. Two of the Howard University students were participants working with students from the University of Benin in the development of the algorithm proposed for real-time VSM computation. The system studies include the use of the PHCN 30-bus, 330-kV high voltage system model.

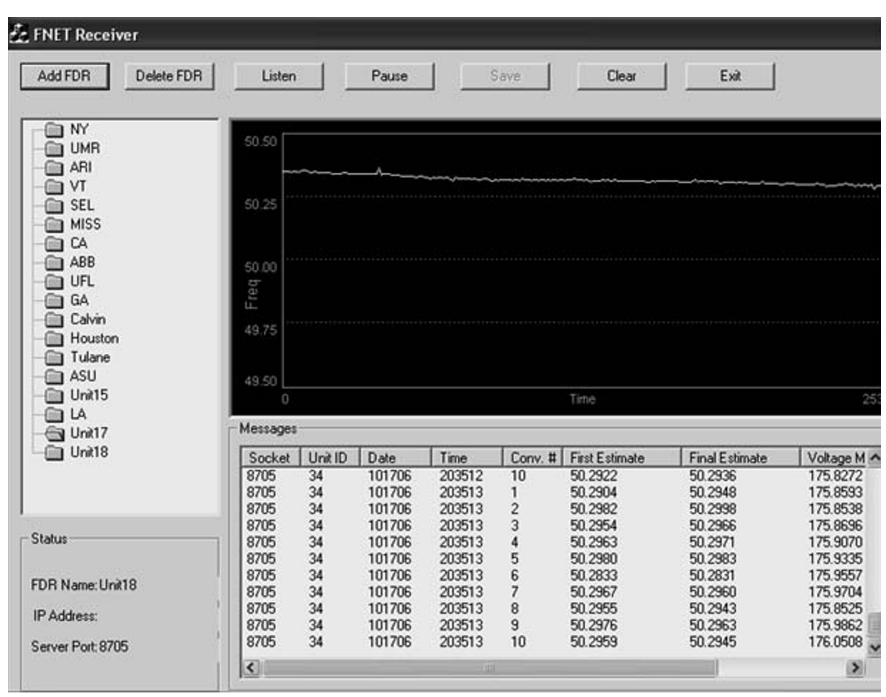

Figure 2. FDR small server program retrieving data at ATBU

\section{B. FDR Recordings in 2006: Analysis and Applications}

After the installation of the FDR several recordings were made in 2006. Preliminary analyses of two representative recordings are reported in [8]. Here, we describe the characteristics of some of these recordings and correlate them to information from the Nigerian National Power Grid. Using both FDR recordings and operations data we have calculated the system frequency response (governing response) $\beta$ [2][3], which is of practical use for utility engineers. Another concern of the Nigerian system operators is the presence of low-frequency oscillations. Using a straightforward method we have estimated the dominant low-frequency modes from several FDR recordings. Finally, an interesting recording which monitored a total system collapse during Dec. 2, 2006 is presented.

1) Disturbance Characteristics and Calculation of $\beta$ : The disturbance events analyzed here are summarized in Table I along with the observed frequency change from the FDR, the reported MW change by the system operators, and the calculated $\beta$.

a) Recording of June 12, 2006: Figure 3 shows the frequency and voltage magnitude recordings taken on this date. The noise present in the recordings can be attributed to a high concentration of nonlinear loads such as uninterruptible power supplies (UPS) and air conditioner units near the FDR. The Savitzky-Golay technique [9] implemented in Origin [10] was used for filtering. The filtered frequency and voltage magnitudes are shown in Fig. $3 \mathrm{c}$ and $3 \mathrm{~d}$. The increase in the system frequency during the first 100 seconds was caused by generation ramping ahead of load pickups. This has been confirmed with the system operators when verifying the GPS time tag of the FDR measurements.

The generation increase and frequency deviation were used to estimate $\beta$ between $21.6-25.65 \mathrm{MW} / 0.1 \mathrm{~Hz}$. Note that the estimated total generation capacity of the system in $2006 \mathrm{did}$ not exceed $3500 \mathrm{MW}$.

b) Recording of June 27, 2006: Figure 4 shows the voltage and frequency traces obtained after filtering the FDR 
Table I

SUMMARY OF DISTURBANCE EVENTS

\begin{tabular}{|l|c|c|c|c|}
\hline DISTURBANCE EVENT & DATE & FREQUENCY CHANGE & MW CHANGE & $\beta(\mathrm{MW} / 0.1 \mathrm{~Hz})$ \\
\hline \hline 1. Generation Increase & $06 / 12 / 2006$ & $+55 \mathrm{mHz}$ & $+118-141 \mathrm{MW}^{*}$ & $21.6-25.65$ \\
2. Loss of Generation & $06 / 12 / 2006$ & $-46 \mathrm{mHz}$ & $-100 \mathrm{MW}$ & 21.74 \\
3. Loss of Kainji Hydro Power Station & $12 / 02 / 2006$ & $-32 \mathrm{mHz}$ & $-70 \mathrm{MW}$ & 21.65 \\
\hline
\end{tabular}

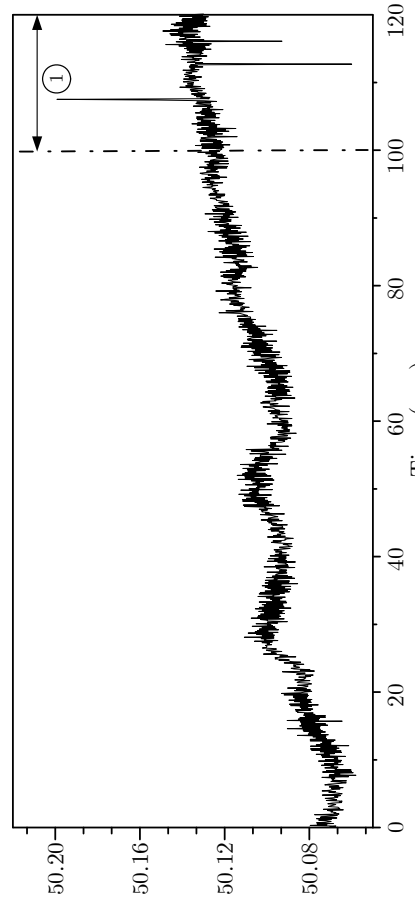

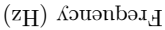

(a) FDR Frequency

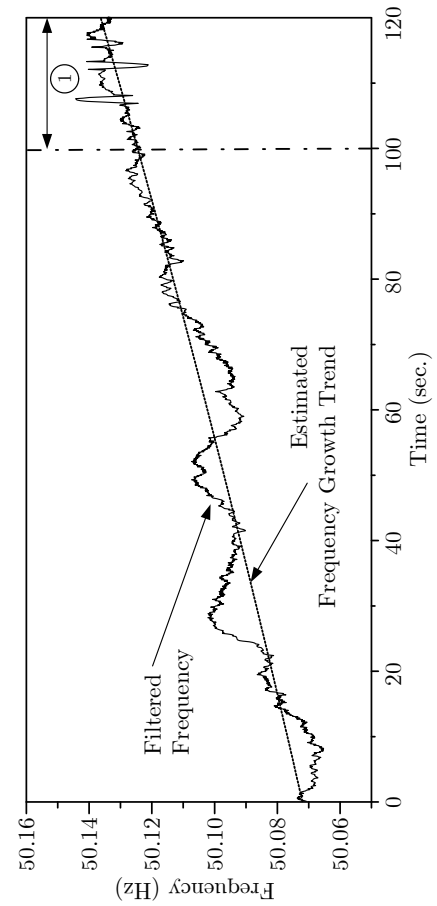

(c) Filtered Frequency

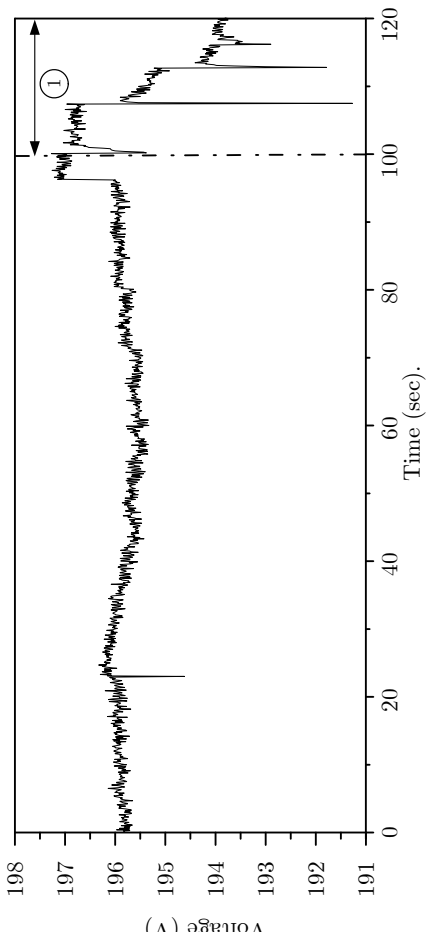

(b) FDR Voltage

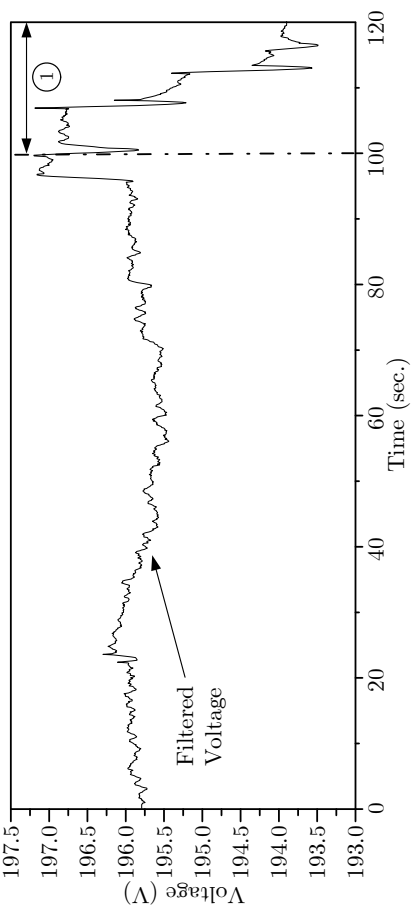

(d) Filtered Voltage
Figure 3. Raw and Filtered FDR Recordings of June 12, 2006

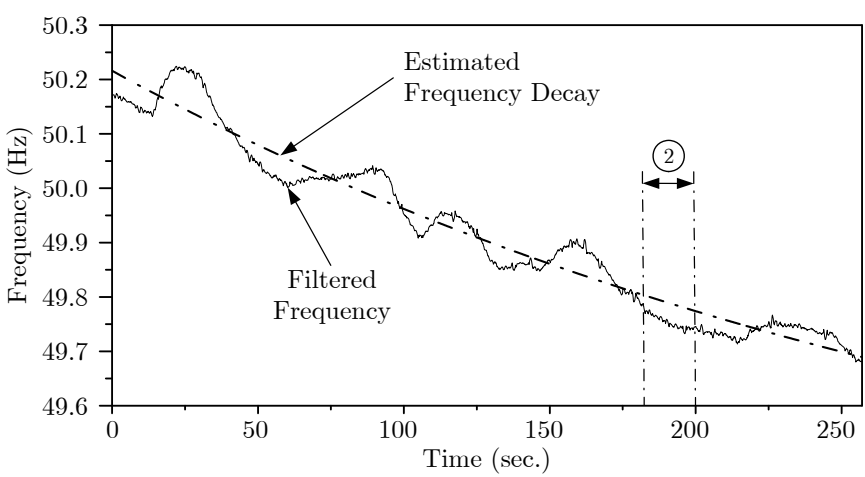

(a) Filtered FDR Frequency

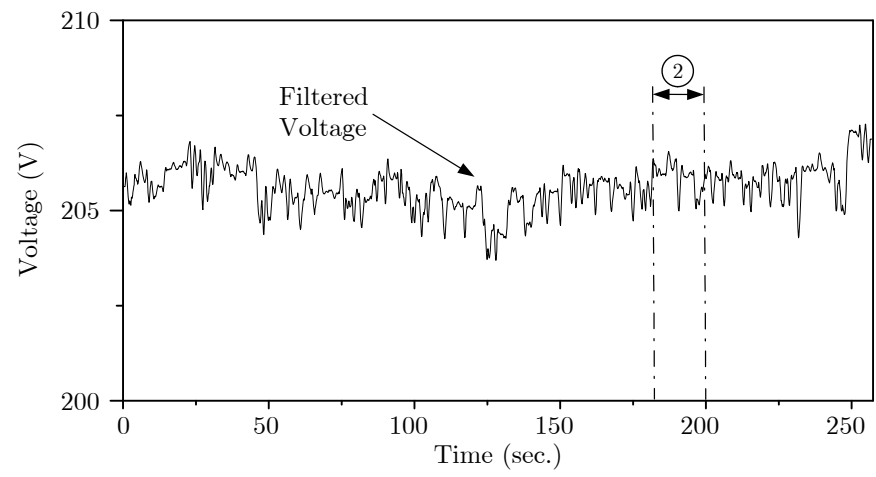

(b) Filtered FDR Voltage

Figure 4. Filtered FDR Recordings of June 27, 2006

measurements. The frequency decay trend was initiated by major loss of generation of approximately $100 \mathrm{MW}$ as indicated by the records of the system operators at the control center. The loss of generation resulted in a frequency drop from 50.18 to $49.72 \mathrm{~Hz}$, and the estimated value of $\beta$ was computed as $21.73 \mathrm{MW} / 0.1 \mathrm{~Hz}$. Poor governor regulation and ineffective load shedding practices can be observed from the FDR recording.

c) Recordings of Dec. 2, 2006: Prolonged recordings were carried to capture data of the system during a typical weekend. Figure 5 shows a segment of the recording taken in the morning while Fig. 6 shows a segment of the recording during the afternoon which will be discussed in Section II-B3. The measurements presented less noise than the previous recordings because they were taken during the weekend, when presumably there were less nonlinear loads connected to the network. Figure 5 shows the FDR recording taken during during the loss of a generating unit at the Kainji Hydro Power Station. The unit was delivering $70 \mathrm{MW}$ when the outage occurred, resulting in a frequency decrease from 50.58 $\mathrm{Hz}$ to $50.26 \mathrm{~Hz}$ in approximately 65 seconds before the disconnection of a major load. From this information $\beta$ was calculated as $21.65 \mathrm{MW} / 0.1 \mathrm{~Hz}$. 


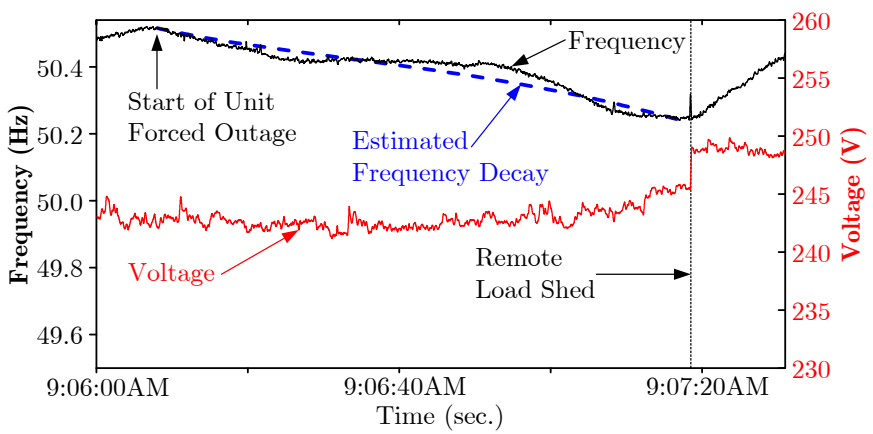

Figure 5. FDR Recording of Dec. 2, 2006 - Kainji Hydro Power Station Unit Loss

Table II

SumMary of Disturbance EVEnTS

\begin{tabular}{|c|c|l|}
\hline $\begin{array}{c}\text { EvENT } \\
\text { No. }\end{array}$ & $\begin{array}{c}\text { TIME } \\
\text { WINDOW (SEC.) }\end{array}$ & $\begin{array}{l}\text { ESTIMATED OSCILLATORY } \\
\text { LOW-FREQUENCIES (Hz) }\end{array}$ \\
\hline \hline 1 & 20 & $0.235,0.275,0.313,0.433,0.469$ \\
2 & 11 & $0.235,0.313,0.470,0.700,0.78$ \\
3 & 11 & $0.234,0.313,0.469,0.546,0.626$ \\
\hline \hline \multicolumn{2}{|c|}{ Common Modes: } & $0.235,0.313,0.469$ \\
\hline
\end{tabular}

2) Estimation of Low-Frequency Oscillations: The disturbances discussed above were analyzed for low-frequency oscillations. The determination of these modes will help to determine the interarea modes in Nigeria once more FDRs are installed and coordinated. The recordings were filtered and the time window used for identification is labeled with a circled number in Figs. 3 and 4.

The following procedure was used to identify the lowfrequency oscillations from the FDR data:

1. Select a suitable disturbance time window of 10-20 sec.

2. Remove unwanted noise and obtain the frequency deviation $(\Delta f)$ from the signal.

3. Apply a band-pass filter with $f_{\min }=0.2 \mathrm{~Hz}$ and $f_{\max }=$ $0.8 \mathrm{~Hz}$ to $\Delta f$.

4. Perform a frequency scan using FFT on the filter output and determine its frequency components.

Table II shows the computed low-frequency modes. The dominant frequencies common to the three events are: 0.235 , 0.313 , and $0.469 \mathrm{~Hz}$. Further studies are being carried out to determine the nature of this oscillatory modes.

3) System Collapse Monitoring: A practical application of the FDR at ATBU has been monitoring of major system disturbances. During 2006 the Nigerian grid suffered twenty one blackouts, the FDR recordings shown in Fig. 6 captured a total system collapse that took place on Dec. 2, 2006.

The system frequency shown in Fig. 6a was relatively stable until 2:10:18 PM when a major disturbance triggered a rapid decay with an estimated decline rate $38.96 \mathrm{mHz} / 0.1$ sec. At this decline rate the frequency dropped from about $50.5 \mathrm{~Hz}$ to $49 \mathrm{~Hz}$ in 24 seconds. Uncoordinated actions from different operators have been determined as the source provoking the collapse. The voltage seen by the FDR shown in Fig. $6 \mathrm{~b}$ suffered a sustained decline rate of $150 \mathrm{mV} / 0.1 \mathrm{sec}$., this might be an indicator that the system is also prone to voltage collapse. Further FDR recordings might confirm this

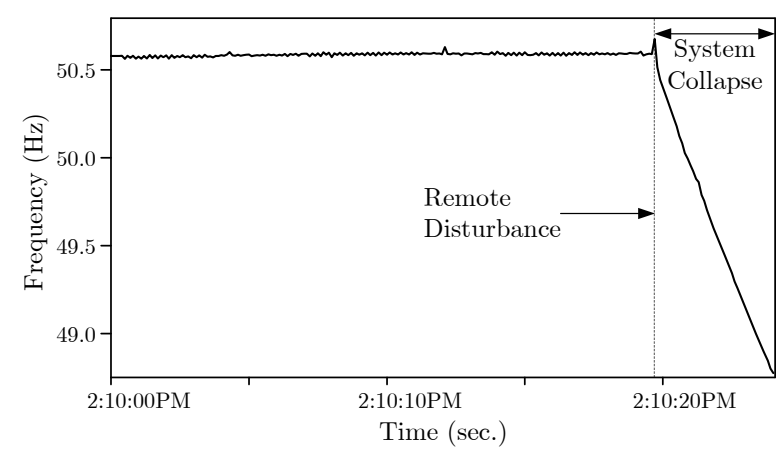

(a) FDR Frequency

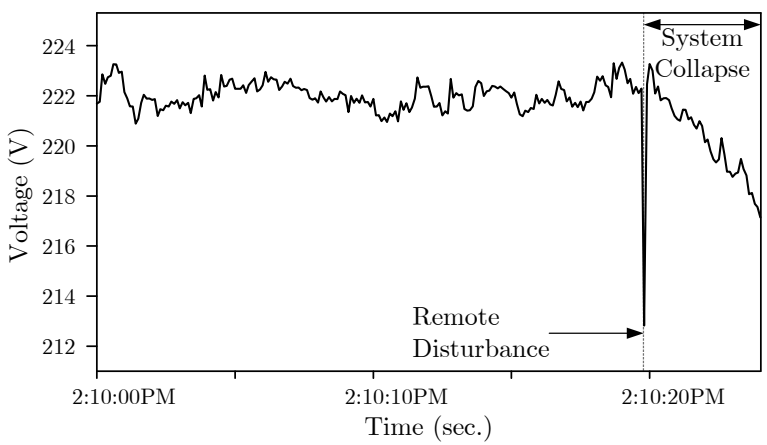

(b) FDR Voltage

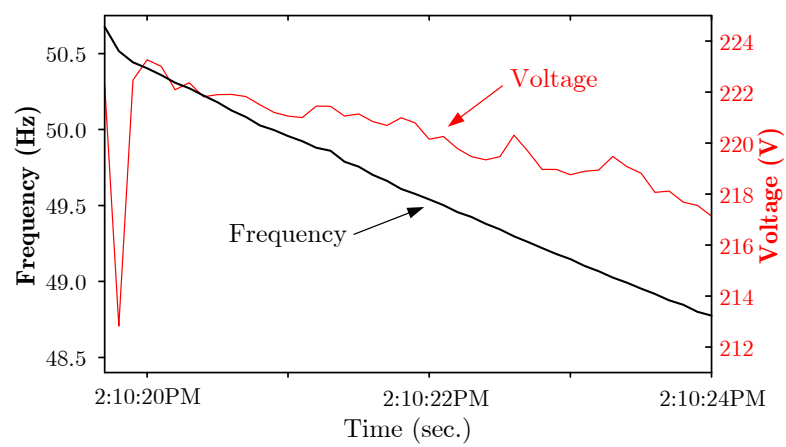

(c) FDR Voltage and Frequency During the System Collapse

Figure 6. FDR Recordings of Dec. 2, 2006 - System Collapse

hypothesis.

This recording shows how the FDR can been of practical use for monitoring and post-mortem analysis of blackouts. The availability of this recordings may aid researchers and engineers to determine means to mitigate future collapses.

\section{Operation Practices}

The interpretations made on the recordings from the FDR are coupled to some of the operation practices of the grid operators for the Nigerian power system. Generally speaking, the range of frequency control is quite large and load shedding is done manually, which significantly affects the system behavior. To better understand the recorded data, system operation practices at Nigeria are described below.

Load is mostly controlled manually. Whenever there is a lack of generation (generation deficiency) the central control center calls local load centers (substations) to manually disconnect a certain amount of MW to bring up the frequency. The frequency deviation acceptable by control center operators 
is $2.5 \%$ of nominal $50 \mathrm{~Hz}$, that is, $\pm 1.25 \mathrm{~Hz}$. The voltage deviation acceptable is $6 \%$ of nominal 230 Volts, that is, 13.8 Volts. SCADA is set up in the control centers, from which frequency is monitored, but no automatic load shedding mechanisms are used. In general, control center operators have a good idea of what the demand is in each load area. They can sequentially connect or disconnect loads. Substations can later disconnect smaller loads on their feeders at their discretion.

Load disconnection when frequency shows a high rate of decay is frequently done at $49.5-49.8 \mathrm{~Hz}$. Frequently, the source of this problem is that substation operators are not able to follow the control center instructions promptly.

\section{Proposed Frequency Monitoring Network}

We propose to install additional FDRs in universities other than ATBU, so that a network of FDRs can form a wide-area monitoring system. This section describes the ideas behind this networked monitoring system.

\section{A. FNET}

The Nigerian university monitoring network will follow the concept of the Frequency Monitoring Network (FNET) [5] conceived by VTech Power IT (Information Technology) Laboratory. The FNET project has been developed as a less expensive alternative recording device to Phasor Measuremet Units (PMUs) [6] and phasor data concentrators (PDCs). Its main goal was to create a wide-area measurement system that could be quickly deployed, be economical, and cover large geographic areas without the need of a dedicated communication infrastructure.

FNET consists of two major components. The first is the FDR which performs GPS synchronized single-phase voltage and frequency data measurement, network interface, and data transmission. It is also a node of the FNET system. The Information Management System (IMS) server is the second component, performing data storage, management, analysis, and user interface. The Internet provides the integrated widearea communication media between the FDRs and the IMS server. A detailed description of the characteristics and architecture of the FNET system can be found in [5].

\section{B. Prospective locations and hosts}

Figure 7 shows the proposed university-based frequency monitoring network for Nigeria. The FDRs will be located at each of the universities in offices or laboratories of the various research collaborators. Table III identifies the universities in the locations shown in Figure 7. Other institutions of higher learning within the country having the requisite facilities and researchers can subsequently link to the network for the purpose of participating in this collaborative research effort. A criterion for selecting a host institutions is the availability of reliable internet facilities. This is because data transfer from wide area distributed FDRs to the IMS server at a central location, requires a reliable internet communication infrastructure.

\section{IMS Server Location}

The issue of the IMS server location is important for the successful implementation of the frequency monitoring network in Nigeria. The ideal location of the IMS server should be one of the proposed host universities with the most extensive internet facility as well as a firm commitment to the success of the project within the overall framework of this US-Africa research collaboration initiative. In the recent past, University of Benin has served as the Nigerian hub for the USAfrica research collaboration effort and with its new expanded internet facility, should be a strong candidate to host the IMS server. It should be mentioned that the Nigerian electric utility also monitors the grid system frequency on a continuous basis at its load control center at Oshogbo, which is within the same geographical zone as the University of Benin.

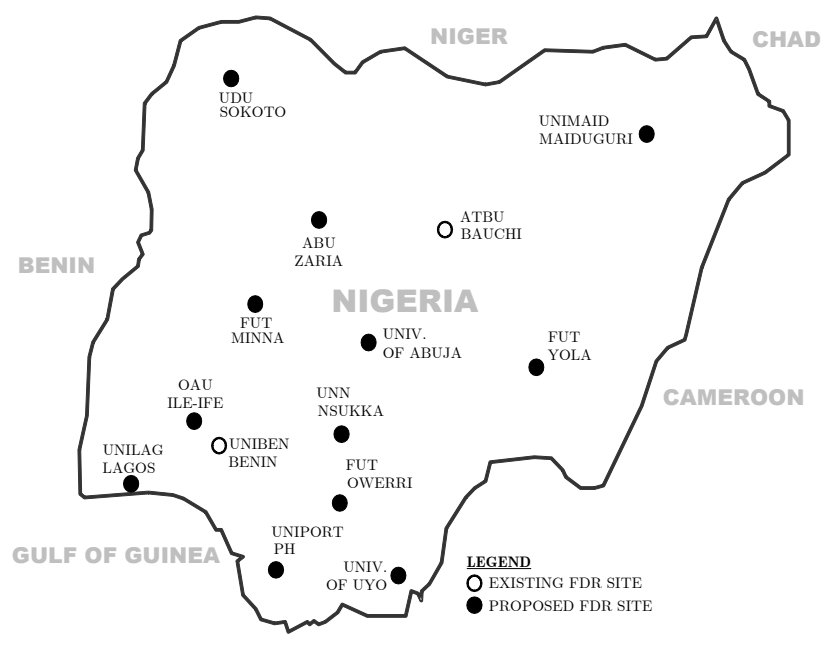

Figure 7. FDR locations for the proposed FNET

Table III

List OF Host UNIVERSITIES OF THE NigERIAN FNET

\begin{tabular}{|c|c|c|}
\hline \multirow{2}{*}{ Acronym } & Host University & City \\
\hline \hline \multicolumn{3}{|c|}{ Existing FDR Sites } \\
\hline ATBU & $\begin{array}{c}\text { Abubakar Tafawa Balewa } \\
\text { University }\end{array}$ & Bauchi \\
\hline UNIBEN & University of Benin & Benin City \\
\hline \hline \multicolumn{3}{|c|}{ Proposed FDR Sites } \\
\hline UDU & $\begin{array}{c}\text { Usumanu Dan Fodio } \\
\text { University }\end{array}$ & Sokoto \\
\hline UNIMAID & University of Maiduguri & Maiduguri \\
\hline ABU & Ahmadu Bello University & Zaria \\
\hline FUT YOLA & $\begin{array}{c}\text { Federal University } \\
\text { of Technology, Yola }\end{array}$ & Yola \\
\hline FUT MINNA & $\begin{array}{c}\text { Federal University } \\
\text { of Technology, Minna }\end{array}$ & Minna \\
\hline UNN & University of Nigeria & Nsukka \\
\hline UNILAG & University of Lagos & Lagos \\
\hline FUT OWERRI & $\begin{array}{c}\text { Federal University } \\
\text { of Technology, Owerri }\end{array}$ & Owerri \\
\hline UNIPORT & University of Port-Harcourt & Choba \\
\hline UNIV. OF ABUJA & University of Abuja & Abuja \\
\hline OAU ILE-IFE & Obafemi Awolowo University & Ile-Ife \\
\hline UNIV. OF UYO & University of Uyo & Uyo \\
\hline
\end{tabular}




\section{Reliability of the proposed Nigerian University FNET}

The proposed FNET when fully implemented should remain in continuous data collection mode 24 hours a day. However, this may not be possible due to various constraints at the host institutions. First, some of the host universities may offer internet service only during daytime. Second, the strength of GPS signals at different locations in Nigeria has not been studied but could significantly affect the operations of the FDRs. The experience gained from the FDR installation at ATBU, Bauchi, indicates that frequent loss of GPS signal is principally responsible for most of the data gaps noticed in some of the recordings so far carried out. The GPS signal strength is significantly affected during heavy cloud overcasts and rainfall. The improvement in the sensitivity of GPS to weak signal is a possible solution to overcome the problem of missing data in FDR recordings.

\section{CONCLUSIONS}

In this paper we have presented the initial results of the joint work between Rensselaer Polytechnic Institute (RPI) and Abubakar Tafawa Balewa University (ATBU) to study frequency dynamics of rapidly growing power systems. The implementation of the FDR at ATBU has provided background information on possible future problems of GPS signal drop and data retrieval. Analysis of data recordings from Bauchi, Nigeria, shows the need for an improvement on frequency control. This highlights a major concern for the deregulation plans of the electricity market at Nigeria. Finally, we have presented a proposal for a university-based frequency monitoring network at Nigeria which would enable researchers from the US and Africa to embark into further research on the understanding of frequency dynamics of rapidly growing power systems. Furthermore, FDRs and an African University FNET can be used to support voltage stability analysis. The overall collaboration of the four universities (ATBU, HU, RPI, and Uniben) also benefit the students by exposing them to different environments and culturally diverse social atmospheres. This activity is valuable to our developing workforce when addressing engineering challenges that have impacts on social issues.

\section{ACKNOWLEDGMENT}

The support provided by Professor Yilu Liu and Mr. Ryan Zuo is gratefully acknowledged. This work is supported in part by NSF grant ECS-0424461 administered by Washington State University, NSF grant ECS-0622119 (Rensselaer Polytechnic Institute), and NSF Grant ECS-0601636 (Howard University).

\section{REFERENCES}

[1] P. Kundur, Power System Stability and Control. New York: McGraw-Hill, 1994.

[2] J.W Ingleson and M. Nagle, "Decline of Eastern Interconnection Frequency Response," in Proceddings of the 1999 Fault and Disturbance Conference, Georgia Tech, May 1999.

[3] J.W. Ingleson and D.M. Ellis, "Tracking the Eastern Interconnection Frequency Governing Characteristic," in Proceedings of the Power Engineering Society General Meeting, Vol. 2, pp. 1461-1466, June 2005.
[4] A. Odubiyi and I.E. Davidson, "Managing the deregulation and privatisation of the Nigerian electricity industry," Africon Conference in Africa, 2002. IEEE AFRICON. 6th, vol.1, no.1, pp. 467- 472, Oct. 2002.

[5] Z. Zhong, C. Xu, B.J. Billian, L. Zhang, S.-J.S. Tsai, R.W. Conners, V.A. Centeno, A.G. Phadke, and Y. Liu, "Power System Frequency Monitoring Network (FNET) Implementation," IEEE Transactions on Power Systems, vol. 20, no. 4, pp. 1914-1921, Nov. 2005.

[6] A.G. Phadke, "Synchronized Phasor Measurements in Power Systems", IEEE Computer Applications in Power, vol. 6, Issue 2, pp. 10-15, Apr. 1993.

[7] Moxa Technologies Co., NPort 5110 Series Manual. First Edition. December 2004. Available online: http://www.moxa.com

[8] L. Vanfretti, Joe H. Chow, and Usman Aliyu, "Building a Frequency Monitoring Network to Study Dynamics of Rapidly Growing Power Systems," in Proceedings of the $7^{\text {th }}$ International Conference on Power System Operations and Planning (ICPSOP), January 2007.

[9] A. Savitzky and M. J. E. Golay, "Smoothing and Differentiation of Data by Simplified Least Squares Procedures," Analytical Chemistry, vol. 36, no. 8, pp. 1627-1639, July 1964.

[10] C. P. Yang, et al., Origin, Northampton, MA: OriginLab Corporation, 2007.

Luigi Vanfretti (Student Memeber '03) received the Electrical Engineering degree from Universidad de San Carlos de Guatemala in 2005. He is pursuing the Ph.D. degree in the Electrical, Computer, and Systems Engineering Department at Rensselaer Polytechnic Institute, from where he obtained his MS in 2007. He was a visiting researcher at the Department of Electronics and Electrical Engineering of The University of Glasgow, Scotland, in Fall 2005. His research interests are modeling, dynamics, and stability of power systems; applications of PMU data, and open source software for power system analysis.

Usman Aliyu (M'78) received the B.Eng. degree with first class honors from Ahmadu Bello University, Zaria, Nigeria, in 1972, the M.S.E.E. degree from Lehigh University, Bethlehem, PA, in 1974, and the Ph.D. degree from Purdue University, West Lafayette, IN, in 1978. He was a member of the faculty of the Ahmadu Bello University from July 1978 to October 1990, the Abubakar Tafawa Balewa University, Bauchi, Nigeria, from November 1990 to August 1992, and the University of Bahrain from September 1992 to July 1996. He was a Visiting Fellow at Argonne National Laboratory in 1986. He is currently a Professor with Abubakar Tafawa Balewa University. His research interests are computer control and modeling of interconnected power systems, voltage collapse phenomenon, optimum var siting and control, and power system security analysis. He has published over 45 papers in international journals.

Joe H. Chow (F'92) received his MS and PhD degrees from the University of Illinois, Urbana-Champaign. After working in the General Electric Power System business in Schenectady, he joined Rensselaer Polytechnic Institute in 1987. He is a professor of Electrical, Computer, and Systems Engineering and the Associate Dean of Engineering for Research and Graduate Programs. His research interests include multivariable control, power system dynamics and control, voltage-sourced converter-based FACTS Controllers, and synchronized phasor data.

James A. Momoh (F'99) received the B.S.E.E. degree from Howard University, Washington, D.C., the M.S.E.E. degree from Carnegie Mellon University, Pittsburgh, PA, the M.Sc. degree in systems engineering from the University of Pennsylvania, Philadelphia, and the Ph.D. in electrical engineering from Howard University, in 1975, 1976, 1980, and 1983, respectively. He is a former Program Director in the Engineering Directorate of the Division of Electrical Communication and Systems (ECS) at the National Science Foundation (NSF) in Arlington, VA. He is also former Chairman of the Electrical Engineering Department at Howard University, and is the Director of the Center for Energy Systems and Control (CESaC) at Howard University. His research interests include power system reliability and power system optimization, automation and intelligent systems, and economics and risk assessment in a deregulated power system environment. He is currently developing an interdisciplinary research/ education program in power, economics, regulation, and environmental adaptive systems. Dr. Momoh has received several awards/honors including the 1987 Presidential Young Investigator Award, and was the recipient of the 1989 ASEE Excellence Educator. 